\title{
Análise da associação da escolaridade com renda e com cuidados de saúde e ectoparasitismo em cães na cidade de Araguaína, Tocantins
}

Francisco BAPTISTA ${ }^{1}$

Monalisa de Sousa Moura

SOUTO ${ }^{1}$

Arielle Nunes MORAIS ${ }^{1}$

Raimunda de Sousa Canêdo

BARROS $^{2}$

Adayanna Karolline Moreira SCHNEIDER ${ }^{1}$

\section{Correspondência para:}

Francisco Baptista, Rua Águas Claras n ${ }^{\circ} 112$ - Setor Noroeste, 77824-230, AraguaínaTO, Fone/Fax: (63) 3414 2332, baptista@uft.edu.br

Recebido para publicação: 15/01/2006 Aprovado para publicação: 28/08/2008

\author{
1 - Escola de Medicina Veterinária e Zootecnia da Universidade Federal do \\ Tocantins, Araguaína-TO \\ 2 - Médica Veterinária Autônoma, Araguaína-TO
}

Resumo

Palavras-chave: Escolaridade. Renda.

Um inquérito epidemiológico realizado em 2005, na cidade de Araguaína, Estado do Tocantins, revelou existir associação entre escolaridade e renda de proprietários de cães $(p<0,01)$. A escolaridade destes proprietários também teve associação com confinamento, vacinação (exceto contra a raiva) e vermifugação dos animais $(p<0,01)$. O ectoparasitismo e a vacinação dos cães contra a raiva foram independentes da escolaridade dos proprietários ( $p>0,05)$. No grupo de proprietários com menor escolaridade, o aumento da instrução formal, para nove ou mais anos, pode reduzir o número de cães sem confinamento, vacinação (exceto contra a raiva) ou vermifugação em $23,3 \%$ (IC95\%=10,9-35,2), 30,5\% (IC95\%=18,7-41,1) e 22,3\% (IC95\%=10,7-33,2), respectivamente; no conjunto de proprietários de cães esta redução pode ser, na mesma ordem, de 10,7\% (IC95\%=0,8-19,3), 14,3\% (IC95\%=3,9-24,3) e 10,7\% (IC95\%=1,019,5). A promoção sócio-econômica regional, com mais ações de educação sanitária e aumento da escolaridade, é condição essencial para a melhoria da saúde dos cães e, conseqüentemente, da saúde pública.

\section{Introdução}

Os parasitas externos, além do incômodo e lesões cutâneas que causam, são importantes transmissores de doença ao cão e deste ao homem, como a dipilidiose, babesiose, ehrlichiose, febre maculosa das montanhas rochosas e doença de Lyme. A raiva e outras doenças infecciosas dos cães continuam tendo ampla distribuição mundial. Infecções pelos estágios larvares de parasitas do gênero Echinococcus são contraídas por pessoas em muitas partes do mundo, por ingestão acidental de ovos eliminados com fezes de cães, que são hospedeiros definitivos desses parasitas. ${ }^{1}$ No Brasil, um inquérito soroepidemiológico realizado no município de Sena Madureira, Estado do Acre, revelou uma prevalência global de contato das pessoas com Echinococcus sp. de 4\%, e prevalências de 6\% e 3,5\% para as áreas rural e urbana, respectivamente ${ }^{2}$; a equinococose é doença comum no Rio Grande do Sul com cistos encontrados em $25 \%$ do gado e $3 \%$ dos ovinos e com 716 casos de acometimento humano entre 1981 e $1999^{3}$. Estudos de contaminação ambiental por ovos e larvas de Toxocara sp. e Ancylostoma sp. têm revelado alto risco para a síndrome da larva migrans no Brasil. ${ }^{4,5,6,7,8}$ Elevada freqüência de anticorpos contra Toxocara sp em pessoas $(39,4 \%)$ foi encontrada no Recife. ${ }^{9}$ Isso mostra que, apesar da relativa facilidade em se proceder ao combate de doenças infecciosas e parasitárias dos cães, elas continuam sendo prevalentes e, por vezes, com freqüências incompatíveis com os recursos profiláticos disponíveis. Esta incompatibilidade entre níveis de ocorrência de doenças e recursos técnicos e científicos disponíveis pode ser devida a fatores como 
instrução formal, educação sanitária e renda dos proprietários. Em um levantamento sobre pobreza e violência no município de São Paulo, constatou-se que nos distritos com maior escolaridade havia diminuído a taxa de pobreza. $^{10}$ Baixo nível de desenvolvimento sócio-econômico regional associado à ausência ou insuficiência de programas de educação sanitária está na base dos deficientes cuidados à saúde dispensados aos animais pelos seus proprietários. ${ }^{11}$ Embora este estudo tenha revelado que muitos proprietários não proporcionam aos seus cães cuidados básicos de saúde e bem estar, não foi encontrada, na bibliografia consultada, abordagem que estabelecesse associação matemática entre essa falta de cuidados e a escolaridade dos proprietários. A escolaridade, contribuindo para a redução da pobreza ${ }^{10}$, pode criar condições, incluindo materiais, que proporcionem melhor qualidade de vida para as pessoas e para os animais de estimação que the fazem companhia. Assim, este estudo tem como objetivo verificar a existência de associação entre escolaridade dos proprietários de cães na cidade de Araguaína e renda familiar, infestação dos cães por ectoparasitas e os seguintes cuidados de saúde dispensados a estes animais: confinamento, vacinação antirábica, vacinação contra outras doenças infecto contagiosas e vermifugação. Objetiva ainda a determinação de razões de prevalência e riscos atribuíveis para as variáveis (exceto renda) associadas à escolaridade.

\section{Material e Método}

Foram feitas 335 entrevistas a pessoas residentes na cidade de Araguaína e que conduziram animais aos postos de vacinação anti rábica, na campanha anual ocorrida em 17 de setembro de 2005. Segundo o Instituto Brasileiro de Geografia e Estatística (IBGE) e pelo censo de 2000, o município de Araguaína tinha uma população de 113.143 habitantes, sendo $93,6 \%$ da área urbana e $6,4 \%$ da zona rural. Estimativa do mesmo órgão, para o município e para 2005, aponta uma população de 127.521 habitantes. Com base em campanhas anteriores de vacinação anti-rábica domiciliar na cidade de Araguaína, o Centro de Controle de Zoonoses (CCZ) local estimava em 13.236 o número de cães da cidade que poderiam ser vacinados na campanha de 2005. ${ }^{12}$ As ações de educação sanitária para doenças infecto-contagiosas de cães têm sido feitas pelo CCZ, limitado-se praticamente ao controle da raiva. De acordo com as disponibilidades humanas e materiais (financeiras e logísticas) foram constituídas seis equipes, cada uma delas com quatro alunos do Curso de Medicina Veterinária da Universidade Federal do Tocantins. As equipes foram previamente treinadas para pesquisa de ectoparasitas (carrapatos, pulgas e piolhos) e aplicação de formulário com as outras variáveis do estudo (renda e escolaridade dos proprietários de cães e confinamento, vacinação e vermifugação destes animais). Por amostragem aleatória simples foram identificados seis postos, entre os 60 estabelecidos pela campanha anual de vacinação anti-rábica, onde seria realizada a coleta de dados da pesquisa. Em cada um dos seis postos foi colocada uma equipe que ali permaneceu em trabalho de pesquisa das $8 \mathrm{~h} 00 \mathrm{~min}$ às $17 \mathrm{~h} 30 \mathrm{~min}$, isto é, até à desmontagem do posto de vacinação pelo CCZ, órgão responsável pela imunização. Os alunos da equipe de trabalho se revezaram no trabalho para almoço e lanche levados ao local. Todas as pessoas que compareceram com cães nos postos onde ocorria a pesquisa foram convidadas a participar da mesma, concedendo entrevista e permitindo a inspeção dos animais. Se o entrevistado conduzisse ao posto de vacinação mais do que um cão do mesmo domicílio e pela facilidade de transmissão dos ectoparasitas entre animais que dividem o mesmo espaço, apenas um dos cães era aleatoriamente alocado para inspeção. Foi levantada informação sobre confinamento, estado vacinal e vermifugação nos 12 meses que antecederam a campanha. Para a vacinação anti-rábica só foram considerados os cães com 15 ou mais meses de idade 
porque apenas eles poderiam ter sido vacinados em duas campanhas anuais consecutivas. Foram considerados arbitrariamente dois níveis de escolaridade: com menos de nove ou com nove ou mais anos de instrução formal. Nesta pesquisa foram considerados os estados de confinamento e de não confinamento. No primeiro o cão não tem acesso à rua e no segundo o cão tem acesso à rua sem qualquer interferência do proprietário. Para esta variável não foram considerados os registros em que os proprietários declararam que os seus cães tinham acesso controlado à rua, $\mathrm{O}$ que se poderia considerar como semiconfinamento. Foi levantada informação sobre a renda do chefe de família, neste caso considerado proprietário dos cães do seu domicílio. Foi constituída uma base de dados informatizada com recurso ao Programa Epi Info 6.04. Foi pesquisada a associação da escolaridade com a renda dos proprietários, com cuidados de saúde dispensados aos cães e com ectoparasitismo nestes animais. As pesquisas de associação pelo teste do $\chi^{2}$ e as determinações das razões de prevalência e dos riscos de não prestação dos cuidados de saúde acima mencionados, aos cães dos proprietários com menor escolaridade e à população de cães em geral, incluindo os respectivos intervalos de confiança (IC95\%), foram feitas com o Programa de computador WINPEPI 1.78.

\section{Resultados e Discussão}

Trinta e um por cento dos 335 entrevistados residiam em nove bairros da área central da cidade e os restantes (69\%) em 12 bairros periféricos. Os números válidos de entrevistas para renda, confinamento, vacinação anti rábica, outras vacinações e vermifugação foram de 216 , 190, 138, 254 e 259, respectivamente.

A distribuição de renda segundo o nível de escolaridade (Tabela 1) mostra associação entre essas variáveis $\chi^{2}=42,6$ e $\mathrm{p}<0,001)$. A freqüência dos proprietários com renda de $\mathrm{R} \$ 900,00$ (USD $\$ 392,38$ ) ou superior é cinco vezes maior no grupo com maior instrução formal (Tabela 1). Embora o aumento de escolaridade aumente a probabilidade de maior renda, dos 216 proprietários com renda declarada, 69 $(31,9 \%)$ auferiam mensalmente $\mathrm{R} \$ 300,00$ ou menos e $136(63,0 \%)$ tinham renda de até $\mathrm{R} \$ 750,00$ (Tabela 1). Como a renda pode limitar, por si só, os gastos com cuidados de saúde, os dados acima não nos permitem admitir, no orçamento da maioria dos proprietários de cães em Araguaína, gastos com cuidados de saúde para estes animais.

Pesquisou-se a presença de parasitas externos em 332 cães. Destes, 128 (38,5\%; IC9 $5 \%=33,2-44,0)$ estavam infestados, sendo $84(25,3 \%$; IC $95 \%=20,7-30,3) \mathrm{com}$ carrapatos, $23(6,9 \%$; IC95\%=4,4-10,2) com pulgas, $20(6,0 \%$; IC $95 \%=3,7-9,1) \mathrm{com}$ carrapatos e pulgas, e um $(0,3 \%$; IC $5 \%=0,0-1,6)$ com piolhos. Estavam infestados 38,1\% (IC95\%=29,6-47,2) e $35,1 \%$ (IC95\%=27,5-43,4) de 126 e 148 cães pertencentes a proprietários de menor e maior escolaridade, respectivamente, o que indica inexistência de associação entre

Tabela 1 - Distribuição da renda mensal dos proprietários de cães, segundo a sua escolaridade, na cidade de Araguaína em 2005

\begin{tabular}{lcccccc}
\hline Renda (R\$) & \multicolumn{6}{c}{ Escolaridade (anos de instrução formal) } \\
\cline { 2 - 8 } & Menos de nove & $\%$ & IC (95\%) & Nove ou mais & IC (95\%) \\
\hline 300 ou menos & 48 & 49,5 & $39,1-59,8$ & 21 & 17,6 & $11,3-25,7$ \\
450 a 750 & 36 & 37,1 & $27,5-47,5$ & 31 & 26,1 & $18,4-34,9$ \\
900 ou mais & 13 & 13,4 & $7,3-21,8$ & 67 & 56,3 & $46,9-65,4$ \\
Total & 97 & 100 & - & 119 & 100 & - \\
\hline
\end{tabular}


escolaridade e infestação por parasitas externos $\left(\chi^{2}=0,26\right.$ e $\left.p>0,05\right)$. Esperava-se que os cães com vida livre, mais expostos ao meio ambiente, apresentassem freqüência significativamente maior de ectoparasitismo. Isso não se verificou porque os dois grupos de escolaridade, apesar de terem apresentado número significativamente diferente de cães com vida livre (Tabela 2), não diferiram quanto à proporção de ectoparasitismo. Um estudo realizado em área urbana no México e compreendendo a um período de três anos, revelou uma prevalência de infestação de cães por carrapatos (Rhipicephalus sanguineus) de $20 \%$, não tendo sido significativamente diferentes as prevalências anuais ou segundo idade e sexo dos animais. ${ }^{13}$ Os autores atribuem a fatores de meio a provável influência sobre esta infestação parasitária. Também neste trabalho a influência sobre a infestação por ectoparasitas pode ser atribuída a fatores de meio e à biologia dos agentes. Essa pode ser a explicação para ausência de associação entre infestação por ectoparasitas e escolaridade.

As percentagens dos cães com confinamento, vacinação (exceto contra a raiva) ou vermifugação são significativamente menores no grupo de proprietários com o mais baixo nível de escolaridade (Tabela 2). Isso pode ser explicado porque a menor renda destes proprietários limita a possibilidade de satisfação das condições de confinamento e das despesas com vacinações (exceto contra a raiva) e vermifugações. Por isso, a vacinação anti rábica, que dispõe de ações de educação sanitária e de vacinação gratuita, se mostrou independente da escolaridade dos proprietários dos cães e apresentou uma proporção global de vacinação $(86,2 \%$; IC95\% $=79,34-91,5)$ significativamente maior que a da vacinação contra outras doenças $(39,8 \%$; IC $95 \%=33,7-46,7)$ $\chi^{2}=78,4$ e $\mathrm{p}<0,01$ (Tabela 2).

Havendo diferença significativa nas freqüências de cuidados de saúde prestados aos cães segundo o nível de escolaridade dos proprietários (Tabela 2), pode-se inferir que o menor nível de escolaridade é fator de risco para a não prestação desses cuidados de saúde (Tabela 3). Ao contrário dos estudos de incidência que medem o risco de se ficar doente, os estudos de prevalência estimam o risco de se estar doente. Assim, no grupo

Tabela 2 - Associação da escolaridade de proprietários de cães com os cuidados de saúde por eles dispensados a esses animais na cidade de Araguaína em 2005

\begin{tabular}{|c|c|c|c|c|c|c|c|c|}
\hline \multirow{2}{*}{\multicolumn{2}{|c|}{ Cuidados de saúde a cães }} & \multicolumn{6}{|c|}{ Escolaridade dos Proprietários de cães (anos) } & \multirow[b]{2}{*}{ Associação } \\
\hline & & Menos de nove & $\%$ & Nove ou mais & $\%$ & Total & $\%$ & \\
\hline \multirow{3}{*}{ Confinamento } & Sim & 54 & 62,1 & 88 & 85,4 & 142 & 74,7 & Sim \\
\hline & Não & 33 & 37,9 & 15 & 14,6 & 48 & 25,3 & $\chi^{2}=13,64$ \\
\hline & Total & 87 & 100 & 103 & 100 & 190 & 100 & $\mathrm{p}<0,01$ \\
\hline \multirow{4}{*}{ Vacinação anti-rábica } & $\operatorname{Sim}$ & 53 & 81,5 & 66 & 90,4 & 119 & 86,2 & Não \\
\hline & Não & 12 & 18,5 & 7 & 9,6 & 19 & 13,8 & $\chi^{2}=2,28$ \\
\hline & Total & 65 & 100 & 73 & 100 & 138 & 100 & $p>0,05$ \\
\hline & Sim & 28 & 23,5 & 73 & 54,1 & 101 & 39,8 & Sim \\
\hline \multirow{3}{*}{$\begin{array}{l}\text { Vacinação } \\
\text { (exceto contra raiva) }\end{array}$} & Não & 91 & 76,5 & 62 & 45,9 & 153 & 60,2 & $\chi^{2}=24,64$ \\
\hline & Total & 119 & 100 & 135 & 100 & 254 & 100 & $p<0,01$ \\
\hline & Sim & 66 & 53,2 & 102 & 75,6 & 168 & 64,9 & Sim \\
\hline \multirow[t]{2}{*}{ Vermifugação } & Não & 58 & 46,8 & 33 & 24,4 & 91 & 35,1 & $\chi^{2}=14,14$ \\
\hline & Total & 124 & 100 & 135 & 100 & 259 & 100 & $\mathrm{p}<0,01$ \\
\hline
\end{tabular}


de proprietários de menor escolaridade existe um risco acrescido que seus cães não estejam confinados, vacinados (exceto contra a raiva) ou vermifugados de $23,3 \%$ $(\mathrm{IC} 95 \%=10,9-35,2), 30,5 \%$ (IC95\% $\%=18,7-$ $41,1)$ e $22,3 \%(\mathrm{IC} 95 \%=10,7 \quad 33,2)$, respectivamente (Tabela 3). Na população geral de cães pertencentes aos proprietários com os dois níveis de escolaridade os riscos acrescidos atribuíveis ao menor nível de escolaridade são de 10,7\% (IC95\% $=0,8-$ 19,3), $14,3 \%$ (IC95\%=3,9 - 24,3) e 10,7\% (IC95\% $\% 1,0-19,5)$ para não confinamento, não vacinação (exceto contra a raiva) e não vermifugação, respectivamente (Tabela 4).

Em curto prazo, a educação sanitária geral da população e a assistência aos mais carentes em meios profiláticos e medicamentosos por parte do poder público e da sociedade, através das suas instituições especializadas, incluindo as Universidades, parece ser a melhor forma de promoção da saúde dos cães e redução dos riscos potenciais que as doenças destes animais podem representar para a saúde pública. Em longo prazo, a redução ou eliminação do papel assistencialista do Estado e da Sociedade requer políticas de promoção sócio econômicas que elevem o nível de escolaridade da população e, conseqüentemente, aumentem a sua participação efetiva na busca e implantação de soluções consistentes de proteção e elevação da saúde animal e humana.

\section{Agradecimentos}

Ao Laboratório de Microbiologia e Imunologia Veterinária da UFT pelo apoio na realização deste levantamento, ao Centro de Controle de Zoonoses de Araguaína por ter permitido a realização das entrevistas e inspeção de cães nos postos de vacinação anti-rábica por ele montados na cidade e aos alunos que participaram do estudo.

Tabela 3 - Riscos de não prestação de cuidados de saúde aos cães do grupo de proprietários de menor escolaridade, na cidade de Araguaína em 2005

\begin{tabular}{lcccccc}
\hline \multirow{2}{*}{ Cuidado Ausente } & \multicolumn{2}{c}{ Freqüência (\%) } & \multirow{2}{*}{ RP (4) } & IC (3) & RA ${ }^{(6)}(\%)$ & IC \\
\cline { 2 - 6 } & Escolaridade I (2) & Escolaridade II (3) & & & & \\
\hline Confinamento & 37,9 & 14,6 & 2,6 & $1,5-4,5$ & 23,3 & $10,9-35,2$ \\
Vacinação (1) & 76,4 & 45,9 & 1,7 & $1,3-2,0$ & 30,5 & $18,7-41,1$ \\
Vermifugação & 46,7 & 24,4 & 1,9 & $1,3-2,7$ & 22,3 & $10,7-33,2$ \\
\hline
\end{tabular}

Tabela 4 - Riscos de não prestação de cuidados de saúde à população de cães, atribuíveis ao mais baixo nível de escolaridade $^{(1)}$ dos proprietários desses animais, na cidade de Araguaína em 2005

\begin{tabular}{|c|c|c|c|c|c|c|}
\hline \multirow{2}{*}{$\begin{array}{l}\text { Cuidado } \\
\text { ausente }\end{array}$} & \multicolumn{2}{|c|}{ Freqüência (\%) } & \multirow{2}{*}{$\mathrm{RP}^{(4)}$} & \multirow{2}{*}{ IC (5) } & \multirow{2}{*}{$\mathrm{RA}^{(6)}(\%)$} & \multirow{2}{*}{ IC } \\
\hline & População & Escolaridade $\Pi^{(3)}$ & & & & \\
\hline Confinamento & 25,3 & 14,6 & 1,7 & $1,02-2,94$ & 10,7 & $0,8-19,3$ \\
\hline Vacinação (2) & 60,2 & 45,9 & 1,3 & $1,06-1,62$ & 14,3 & $3,9-24,3$ \\
\hline Vermifugação & 35,1 & 24,4 & 1,4 & $1,02-2,02$ & 10,7 & $1,0-19,5$ \\
\hline
\end{tabular}

\section{Analysis of the association of the schooling with income and with cares of health and ectoparasitism in dogs in the city of Araguaína, Tocantins}

\section{Abstract}

An epidemiological survey carried out in 2005, in the city of Araguaína, State of the Tocantins, revealed to exist association between schooling and income of dogs' owners $(\mathrm{p}<0,01)$. The schooling of these owners
Key words:

Schooling. Income.

Parasitism.

Care of health.

Public health. Dogs. 
also had association with confinement, vaccination (except against the rabies) and deworming $(p<0.01)$. The ectoparasitism and the dogs' vaccination against the rabies were independent of the schooling of the owners $(p>0,05)$. In the group of owners with smaller schooling, the increase of the formal instruction, for nine or more years, can reduce the number of dogs without confinement, vaccination (except against the rabies) or deworming in 23,3\% (IC95\%=10,935,2), 30,5\% (IC95\%=18,7-41,1) and 22,3\% (IC95\%=10,7-33,2), respectively; in the assembly of all of the owners of dogs this reduction can be, in the same order, of $10.7 \%$ (IC95\%=0,8-19,3), $14.3 \%(\mathrm{IC} 95 \%=3,9-24,3)$ and $10.7 \%$ (IC95\%=1,0-19,5). The regional socio-economic promotion, with more actions of sanitary education and increase of the schooling, is essential condition to the improvement of the health of the dogs and, consequently, of the public health.

\section{Referências}

1 SCHANTZ, P. M.; WANG, H.; QIU, J.; LIU, F. J.; SAITO, E.; EMSHOFF, A.; ITO, A.; ROBERTS, J. M.; DELKER, C. Echinococcosis on Tibetan Plateau: prevalence and risk factors for cystic and alveolar echinococcosis in Tibetan populations in Qinghai Province, China. Parasitology, v. 127, p. S109-S120, 2003. Supplement S1.

2 PASTORE, R.; VITALI, L. H.; MACEDO, V. O.; PRATA, A. Inquérito sorológico da infecção pelo Echinococcus sp no município de Sena Madureira, AC. Revista da Sociedade Brasileira de Medicina Tropical, v. 36, n. 4, p. 473-477, 2003.

3 FARIAS, L. N.; MALGOR, R.; CASSARAVILLA, C. BRAGANÇA, C.; DE LA RUE, M. L. Echinococcosis in Southern Brazil: efforts toward inplementation of control program in Santana do Livramento, Rio Grande do Sul. Revista do Instituto de Medicina Tropical de São Paulo, v. 46, n. 3, p. 153-156, 2004. Disponível em: <http://www.scielo.br/pdf/rimtsp/v46n3/ 20720.pdf >. Acesso em: 06 out. 2005.

4 ARAÚJO, F. R.; CROCCI, A. J.; RODRIGUES, R. G. C.; AVALHAES, J. S.; MIYOSHI, M. I.; SALGADO, F. P.; SILVA, M. A.; PEREIRA, M. L. Contaminação de praças públicas de Campo Grande, Mato Grosso do Sul, Brasil, por ovos de Toxocara e Ancylostoma em fezes de cães. Revista da Sociedade Brasileira de Medicina Tropical, v. 32, n. 5, p. 581-583, 1999. Disponível em: <http://www.scielo.br/pdf/rsbmt/ v32n5/0848.pdf >. Acesso em: 06 out. 2005.

5 CAPUANO, D. M.; ROCHA, G. M. Environmental contamination by Toxocara sp. eggs in Ribeirão Preto, São Paulo State, Brazil. Revista do Instituto de Medicina Tropical de São Paulo, v. 47, n. 4, p. 223-226, 2005. Disponível em: <http://www.scielo.br/pdf/rimtsp/ v47n4/25661.pdf > . Acesso em: 06 out. 2005.

6 CASTRO, J. M.; SANTOS, S. V.; MONTEIRO, N. A. Contaminação de canteiros da orla marítima do Município de Praia Grande, São Paulo, por ovos de Ancylostoma e Toxocara em fezes de cães. Revista da Sociedade Brasileira de Medicina Tropical, v. 38, n. 2, p. 199-201, 2005. Disponível em: <http:// www.scielo.br/pdf/rsbmt/v38n2/23584.pdf > . Acesso em: 06 out. 2005.

7 NUNES, C. M.; PENA, F. C.; NEGRELLI, G. B.; ANJO, C. G. S.; NAKANO, M. M.; STOBBE, N. S. Ocorrência de larva migrans na areia de áreas de lazer das escolas municipais de ensino infantil. Araçatuba, SP, Brasil. Revista de Saúde Pública, v. 34, n. 6, p. 656-658, 2000.

8 SANTARÉM, V. A.; SARTOR, I. F.; BERGAMO, F. M. M. Contaminação, por ovos de Toxocara spp, de parques e praças públicas de Botucatu, São Paulo, Brasil. Revista da Sociedade Brasileira de Medicina Tropical, v. 31, n. 6, p. 529-532, 1998.

9 AGUIAR-SANTOS, A. M.; ANDRADE, L. D.; MEDEIROS, Z.; CHIEFFI, P. P.; LESCANO, S. Z.; PEREZ, E. P. Human toxocariasis: frequency of anti- Toxocara antibodies in children and adolescents from an outpatient clinic for lymphatic filariasis in Recife, Northeast Brazil. Revista do Instituto de Medicina Tropical de São Paulo, v. 46, n. 2, 2004. Disponível em: <http://www.scielo.br/pdf/rimtsp/v46n2/ 19889.pdf>. Acesso em: 10 out. 2005.

10 POCHMANN, M. Pobreza e violência no município de São Paulo. São Paulo: Rede Social de Justiça e Direitos Humanos, 2002. Disponível em: <http:// www.social.org.br/relatorio2002/relatorio019.htm > . Acesso em: 6 out. 2005.

11 SOUZA, L. C.; MODOLO, J. R.; PADOVANI, C.R.; MENDONÇA, A. O.; LOPES, A. L. S.; SILVA, W. B. S. Posse responsável de cães no Município de BotucatuSP: realidades e desafios. Revista de Educação Continuada do CRMV, v. 5, n. 2, p. 226-232, 2002.

12 GOMES, L. C. Estimativa de Cães [mensagem pessoal]. Mensagem recebida por <e-mail> em 14 mai. 2008.

13 VAZQUEZ, C. C.; VAZQUEZ, Z. G.; SOTO, M. M. Prevalence of Rhipicephalus sanguineus infestation in dogs in Cuervanaca, Morelos, México. Parasitología al dia, v. 22, n. 1-2, 1998. Disponível em: <http:// www.scielo.cl/scielo.php?pid=S0716$07201998000100005 \&$ script $=$ sci_arttext\&tlng $=\mathrm{em}>$. Acesso em: 07 jan. 2005. 